\title{
MAPEAMENTO DO USO E DA COBERTURA ATUAL DA TERRA PARA INDICAÇÃO DE ÁREAS DISPONÍVEIS PARA RESERVAS LEGAIS: ESTUDO EM NOVE MUNICÍPIOS DA REGIÃO AMAZÔNICA ${ }^{1}$
}

\author{
Elaine Cristina Cardoso Fidalgo ${ }^{2}$, Edison Crepani $^{3}$,Valdete Duarte ${ }^{4}$, Yosio Edemir Shimabukuro ${ }^{5}$, Rita Marcia da
}

Silva Pinto ${ }^{6}$ e Sérgio Lopes Dousseau ${ }^{7}$

\begin{abstract}
RESUMO - O presente trabalho foi realizado com o objetivo de indicar as áreas disponíveis para manutenção de reserva legal, com a finalidade de fornecer subsídios à discussão sobre a extensão das reservas legais na Amazônia brasileira. A metodologia empregada foi dividida em duas etapas: a primeira envolveu a delimitação das áreas originais de ocorrência de formações florestais e de cerrado e a identificação das áreas sobre as quais recai a obrigatoriedade de manutenção de reserva legal; a segunda envolveu a identificação dos remanescentes vegetais disponíveis para manutenção de reservas legais, bem como das áreas que foram alteradas, realizada a partir do mapeamento do uso e da cobertura atual das terras, utilizando técnicas de processamento digital de imagens e geoprocessamento. O estudo foi aplicado em nove municípios da Amazônia Oriental (quatro municípios no Pará e cinco no Maranhão). Os resultados obtidos com base nas imagens TM Landsat do ano de 1999 mostram que todos os municípios estudados apresentaram valores inferiores a $80 \%$ de florestas remanescentes. Os municípios do Pará apresentaram sua área de remanescentes florestais um pouco superior a $60 \%$, enquanto os do Maranhão apresentaram valores mais baixos, inferiores a 50\%, chegando a 6,46\% em Itinga do Maranhão.
\end{abstract}

Palavras-chave: Reserva Legal, uso e cobertura da terra, sensoriamento remoto, processamento digital de imagens, geoprocessamento.

\section{LAND USE AND COVER MAPPING TO IDENTIFY AVAILABLE AREAS FOR LEGAL RESERVE IN NINE MUNICIPALITIES IN THE AMAZONIA REGION}

\begin{abstract}
This work was carried ou to indicate the available areas for legal reserve maintenance aiming to provide a basis for discussing the issue of extending legal reserve areas in the Brazilian Amazonia. The methodology employed was divided into two stages: the first involved the delimitation of the original limits of the forest and savanna (cerrado) vegetations, and the identification of the areas where legal reserve must be maintained; the second stage involved the identification of the remaining vegetation cover available for maintaining the legal reserve areas, as well as the disturbed areas through land cover and use mapping using digital image processing and geoprocessing techniques. The study was applied in nine municipalities in Eastern Amazonia (four municipalities in the state of Pará and five in Maranhão). The results obtained using Landsat TM data of 1999 show that all the municipalities studied presented values lower than $80 \%$ of the remaining forest. The municipalities in Pará presented remaining forest areas a little over 60\%, while in Maranhão municipalities presented values lower than 50\%, reaching $6.46 \%$ in Itinga do Maranhão.
\end{abstract}

Key words: $\quad$ Legal Reserve, land use and cover, remote sensing, digital image processing, geoprocessing.

1 Recebido para publicação em 25.4.2002.

Aceito para publicação em 4.11.2003.

2 EMBRAPA,Rua Jardim Botânico, 1024, 22460-000 Rio de Janeiro-RJ, <efidalgo@ cnps.embrapa.br>. ${ }^{3}$ INPE, Av. dos Astronautas, 1758, 12270-010 São José dos Campos-SP, <crepani@ltid.inpe.br>; ${ }^{4}$ INPE, <valdete@ltid.inpe.br>; ${ }^{5}$ INPE, <yosio@ltid.inpe.br>. ${ }^{6}$ BookImage, Rua Colômbia, 83, 12223-090 São José dos Campos-SP, <rita@ bookimage.com.br>. ${ }^{7}$ FUNCATE, Rua Euclides Miragaia, 433, $1^{\circ}$ andar, 12221-830 São José dos Campos-SP, <sergio@ geo.funcate.org.br>. 


\section{INTRODUÇÃO}

O debate atual envolvendo a proporção de florestas a serem delimitadas como reservas legais na Amazônia Legal Brasileira tem demonstrado a deficiência de informações sobre a região, incluindo dados sobre o uso e a cobertura atual de suas terras e sua distribuição no espaço.

Atualmente em vigor, a Medida Provisória no 2.16667, de 24 de agosto de 2001, estabelece:

"Art. 1o Os arts 1o 4o 14, 16 e 44, da Lei no 4771, de 15 de setembro de 1965, passam a vigorar com as seguintes redações:

\section{Art. 1…}

$\S 2$ o Para os efeitos deste Código, entende-se por:...

III - Reserva Legal: área localizada no interior de uma propriedade ou posse rural, excetuada a de preservação permanente, necessária ao uso sustentável dos recursos naturais, à conservação e reabilitação dos processos ecológicos, à conservação da biodiversidade e ao abrigo e proteção de fauna e flora nativas;...

Art. 16. As florestas e outras formas de vegetação nativa, ressalvadas as situadas em área de preservação permanente, assim como aquelas não sujeitas ao regime de utilização limitada ou objeto de legislação específica, são suscetíveis de supressão, desde que sejam mantidas, a título de reserva legal, no mínimo:

I - oitenta por cento, na propriedade rural situada em área de floresta localizada na Amazônia Legal;

II - trinta e cinco por cento, na propriedade rural situada em área de cerrado localizada na Amazônia Legal, sendo no mínimo vinte por cento na propriedade e quinze por cento na forma de compensação em outra área, desde que esteja localizada na mesma microbacia, e seja averbada nos termos do $\S 7^{\circ}$ deste artigo;...”

Conforme se observa no texto da Medida Provisória, a reserva legal é definida como um porcentual da área de cada propriedade ou posse rural, e esse porcentual varia em função dos tipos de vegetação que ocorrem em suas áreas - floresta, cerrado ou campos.

Assim, para identificação das áreas disponíveis para manutenção de reserva legal na região Amazônica tornase necessário definir, inicialmente, os limites originais de ocorrência das formações florestais e de cerrado e as áreas sobre as quais recai a obrigatoriedade de manutenção de reserva legal (propriedades e posses rurais).
Em seguida, deve-se identificar, nessas áreas, a vegetação remanescente e verificar se ela atinge o porcentual estabelecido.

Estudos da cobertura vegetal e do uso da terra na Amazônia, utilizando imagens orbitais, têm sido relatados com freqüência na literatura. Os trabalhos pioneiros de Tardin et al. (1979), Shimabukuro et al. (1982) e Santos et al. (1983) foram realizados com imagens do sensor MSS Landsat (sensor "Multispectral Scanner Subsystem" do satélite Landsat). SANO et al. (1989) utilizaram as imagens TM Landsat (sensor "Thematic Mapper" do satélite Landsat) no formato digital para o mapeamento do uso das terras, fazendo a caracterização e quantificação de classes de paisagem em dez municípios do nordeste paraense. Barroso et al. (1993), usando técnicas de sensoriamento remoto e geoprocessamento, mostraram a importância dessas técnicas na detecção de mudanças no uso da terra por transformações antrópicas ocorridas na cobertura vegetal para áreas de projeto de assentamento na região de Paragominas (Estado do Pará). Alves \& Skole (1996) e Moran et al. (1994) usaram a análise multitemporal e o armazenamento periódico dos dados de sensoriamento remoto da Amazônia para entendimento dos diferentes padrões de regeneração secundária, além das mudanças da cobertura e do uso da terra.

O presente trabalho foi realizado tendo como objetivo o desenvolvimento de um indicador das áreas disponíveis para manutenção de reserva legal na Amazônia a partir do levantamento da vegetação remanescente, utilizando imagens do sensor TM Landsat, e de dados secundários disponíveis sobre os limites originais de ocorrência das formações vegetais. $\mathrm{O}$ estudo foi aplicado a nove municípios da Amazônia Oriental (quatro municípios no Pará e cinco no Maranhão). Pretendeu-se com isso fornecer elementos que enriquecessem a discussão sobre a extensão das reservas legais na Amazônia brasileira.

\section{MATERIAL E MÉTODOS}

A área de estudo totaliza aproximadamente $49.000 \mathrm{~km}^{2}$ e está compreendida entre as coordenadas $02^{\circ} 23^{\prime}$ e $05^{\circ} 40^{\prime}$ de latitude sul e $46^{\circ} 22^{\prime}$ e $49^{\circ} 03^{\prime}$ de longitude oeste, sendo coberta por cinco cenas do sensor "Thematic Mapper" (TM) do satélite Landsat, as quais estão descritas no Quadro 1.

A metodologia empregada foi dividida em duas etapas: a primeira envolveu a delimitação das áreas originais de ocorrência de formações florestais e de 
cerrado e a identificação das áreas sobre as quais recai a obrigatoriedade de manutenção de reserva legal; a segunda envolveu a identificação dos remanescentes vegetais disponíveis para delimitação de reservas legais e das áreas que foram alteradas, realizada a partir do levantamento do uso e da cobertura atual das terras.

Quadro 1 - Datas das imagens do sensor TM Landsat Table 1 - Landsat TM image dates

\begin{tabular}{|c|c|}
\hline CENA & DATA \\
\hline $222 / 62$ & $14 / 07 / 1999$ \\
$222 / 63$ & $14 / 07 / 1999$ \\
$222 / 64$ & $14 / 07 / 1999$ \\
$223 / 62$ & $05 / 07 / 1999$ \\
$223 / 63$ & $05 / 07 / 1999$ \\
\hline
\end{tabular}

\subsection{Delimitação das Áreas Originais de Ocorrência de Formações Florestais e de Cerrado e Identifi- cação das Áreas Para Manutenção de Reserva Legal}

No presente trabalho, os limites originais de ocorrência de floresta e cerrado foram traçados com base nos dados dos Mapas Fitoecológicos Folhas SA-22 Belém, SA-23/24 São Luís/Fortaleza, SB/SC-22 Araguaia/ Tocantins, SB-23/24 Teresina/Jaguaribe do PROJETO RADAMBRASIL (1973/1974).

As fitofisionomias que ocorrem na região foram agrupadas nas categorias:

- Florestas, reunindo as formações florestais (Florestas Ombrófilas Densas, Estacionais e Secundárias e Savana Arbórea Densa); e

- Cerrados, reunindo as formações de savana de porte não-florestal (Savana Arborizada e Savana Parque).

As áreas classificadas nos Mapas Fitoecológicos do Projeto RADAMBRASIL como Agropecuária, por serem de ocupação antiga, não foram incluídas no cálculo da reserva legal ${ }^{1 /}$.

1/ Essas áreas totalizam $799 \mathrm{~km}^{2}$ ou 2,63\% da área estudada, estando localizadas nos municípios de Paragominas e Ulianópolis, no Pará.
Em função da ausência de dados referentes aos limites das propriedades e posses rurais na área de estudo, foi realizada uma estimativa das áreas rurais, por município, em que recai a obrigatoriedade da manutenção da reserva legal. Para essa estimativa excluiu-se da área estudada dos municípios:

- as áreas das unidades de conservação e terras indígenas² ${ }^{\prime}$, para as quais não está prevista a obrigatoriedade de manutenção de reserva legal;

- as áreas urbanas delimitadas no mapa de Uso e Cobertura da Terra;

- os espelhos d'água (rios, lagos e represas) delimitados no mapa de Uso e Cobertura da Terra; e

- as áreas encobertas por nuvens ${ }^{3 /}$.

\subsection{Identificação dos Remanescentes Vegetais e das Áreas Alteradas}

A delimitação dos remanescentes vegetais foi feita através da interpretação de imagens do sensor TM Landsat-5, bandas $3(0,52-0,59 \mu \mathrm{m}), 4(0,63-0,69 \mu \mathrm{m})$ e $5(1,55-1,75 \mu \mathrm{m})$, utilizando técnicas de processamento digital. A metodologia utilizada neste trabalho foi desenvolvida por Crepani et al. (2001), tendo sido adaptada do projeto de mapeamento digital das áreas desflorestadas da Amazônia Legal (PRODES DIGITAL) (Duarte et al., 1999).

Primeiramente, foram geradas imagens-fração vegetação, solo e sombra através do modelo linear de mistura espectral (Shimabukuro \& Smith, 1991). As imagens-fração resultantes foram reamostradas para a resolução de 60 × $60 \mathrm{~m}$. Com base na experiência do projeto PRODES DIGITAL, esta reamostragem minimiza o tempo de processamento, sem prejudicar o resultado de classificação, considerando o produto final compatível com a escala 1:250.000.

2/ Os limites de unidades de conservação estaduais e federais e terras indígenas foram obtidos através do Sistema de Informações de Unidades de Conservação (SIUC), fornecido pelo IBẢMA.

3/ Foram excluídas das análises as áreas que apresentaram coberturas de nuvens nas imagens utilizadas no levantamento do uso e cobertura da terra, devido à ausência de informações sobre remanescentes e áreas alteradas. Elas estão localizadas no município de Paragominas e correspondem a 0,03\% da área do município.

R. Árvore, Viçosa-MG, v.27, n.6, p.871-877, 2003 
Em seguida, a imagem-fração sombra foi segmentada. O procedimento usado para a segmentação de imagens foi baseado no algoritmo de "crescimento de região" (Zucker, 1976), utilizando os limiares 8 (similaridade ou distância mínima entre valores digitais) e 16 (área mínima, em número de pixels). Uma descrição detalhada do processo de segmentação pode ser encontrada em Batista et al. (1994).

Na Figura 1 está um exemplo das linhas de segmentação geradas sobre a imagem-fração sombra.

As imagens-fração segmentadas foram classificadas de forma não-supervisionada com base em um algoritmo de agrupamento ("Clustering"), denominado ISOSEG (Bins et al., 1992).

As classes de uso e cobertura da terra, posteriormente mapeadas e editadas, foram:

- Floresta: áreas cobertas por vegetação de porte florestal (Florestas Ombrófilas Densas, Florestas Estacionais e Savana Arbórea Densa).
- Cerrado: áreas cobertas por vegetação de savana de porte não-florestal.

- Vegetação em Regeneração: área interpretada nas imagens como vegetação em estádio médio ou avançado de regeneração.

- Atividade Agrossilvopastoril: áreas de ocorrência de atividades agrícolas, pastoris ou de reflorestamento.

- Pasto-Sujo: área em que houve o corte raso da vegetação natural e, em geral, o desenvolvimento de alguma atividade agropastoril e que se encontra no início do processo de regeneração, sendo ocupada por espécies pioneiras, principalmente o babaçu (Orbignya phalerata).

- Área Urbanizada: área com feição característica de ocupação urbana observada nas imagens.

- Nuvem: área onde a presença de nuvem nas imagens utilizadas impossibilitou a delimitação e classificação do uso e da cobertura da terra.

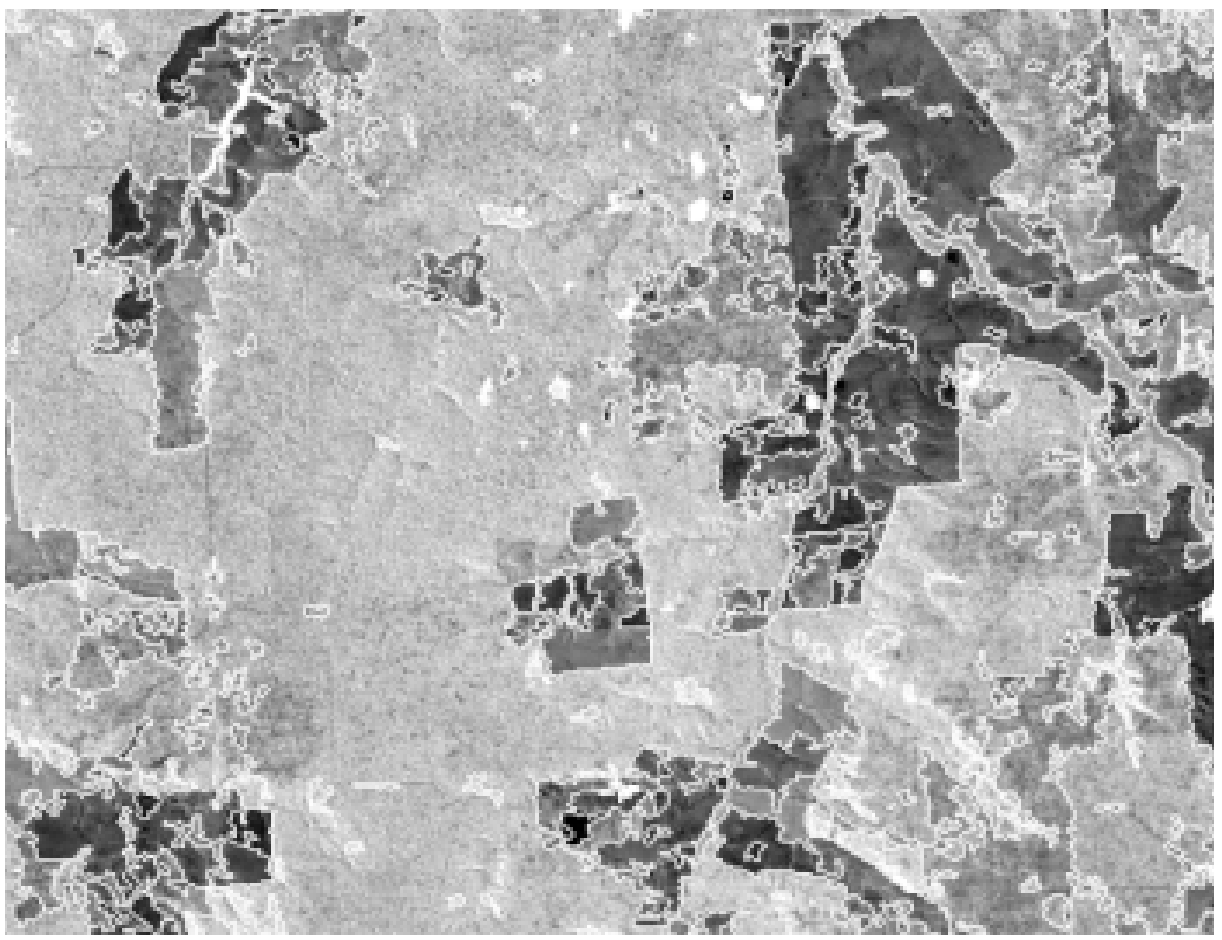

Figura 1 - Linhas de segmentação (cor branca) sobre parte da imagem-fração sombra da cena 223/62, do sensor TM. Figure 1 - Segmentation lines (in white) over part of the shade fraction image of TM scene 223/62. 
A classe Floresta, bem como as áreas desflorestadas, foi mapeada com o uso da imagem-fração sombra. Posteriormente, após a separação dos temas citados, as imagens-fração solo e vegetação foram utilizadas para discriminar áreas ocupadas com Vegetação em Regeneração, Atividade Agrossilvopastoril e Pasto-Sujo. As áreas ocupadas com vegetação de savana de porte nãoflorestal foram separadas daquelas onde ocorrem formações florestais, utilizando as informações auxiliares dos Mapas Fitoecológicos do Projeto RADAMBRASIL, além do mosaico de imagens AVHRR do satélite NOAA. As áreas de savanas foram mapeadas como Floresta (Savana Arbórea Densa) e Cerrado (Savana Arborizada e Savana Parque). A classe Área Urbanizada foi delimitada sobre a composição colorida das imagens.

Para este trabalho, também foram utilizadas fotografias aéreas amostrais da área de estudo e um mosaico de fotografias aéreas que abrangeu toda a bacia do rio Itinga. Essas fotografias estão na escala 1:25.000 e foram utilizadas com o objetivo de dar suporte a validação da classificação das imagens.

As classes de uso da terra delimitadas foram agrupadas para contabilização da extensão das áreas ocupadas por vegetação remanescente e alterada de Floresta e de Cerrado:

- Área Remanescente de Floresta: área classificada como Floresta ou Vegetação em Regeneração.

- Área Remanescente de Cerrado: área classificada como Cerrado.

- Área Alterada de Floresta e Cerrado: área classificada como Atividade Agrossilvopastoril ou Pasto-Sujo em região de ocorrência de Floresta e Cerrado (segundo os dados do Projeto RADAMBRASIL), respectivamente.

$\mathrm{O}$ indicador das áreas de remanescentes florestais disponíveis para manutenção de reserva legal foi obtido através da equação:

$$
P_{F R}=\frac{F_{R}}{\left(F_{R}+F_{A}\right)} 100
$$

em que $P_{F R}=$ porcentagem de áreas de remanescentes florestais disponível para manutenção de reserva legal; $F_{R}=$ extensão de área remanescente de Floresta em quilômetros quadrados; e $F_{A}=$ extensão de área alterada de Floresta em quilômetros quadrados.
$\mathrm{O}$ indicador das áreas de remanescentes de Cerrado disponíveis para manutenção de reserva legal foi obtido através da equação:

$$
P_{C R}=\frac{C_{R}}{\left(C_{R}+C_{A}\right)} 100
$$

em que $P_{C R}=$ porcentagem de áreas de remanescentes de Cerrado disponível para manutenção de reserva legal; $C_{R}=$ extensão de área remanescente de Cerrado em quilômetros quadrados; e $C_{A}=$ extensão de área alterada de Cerrado em quilômetros quadrados.

Todas as variáveis foram totalizadas para as áreas sobre as quais recai a obrigatoriedade de manutenção de reserva legal, sendo os resultados apresentados por município.

\section{RESULTADOS E DISCUSSÃO}

Na Figura 2 está a distribuição das áreas em que recai a obrigatoriedade de manutenção de reserva legal, ou seja, as áreas originais de ocorrência de Floresta, excluídas as unidades de conservação e terras indígenas, as áreas atualmente urbanizadas e ainda as áreas de ocupação antiga. As áreas de Cerrado, nuvens e corpos d'água, devido à menor extensão, não podem ser visualizadas nessa escala.

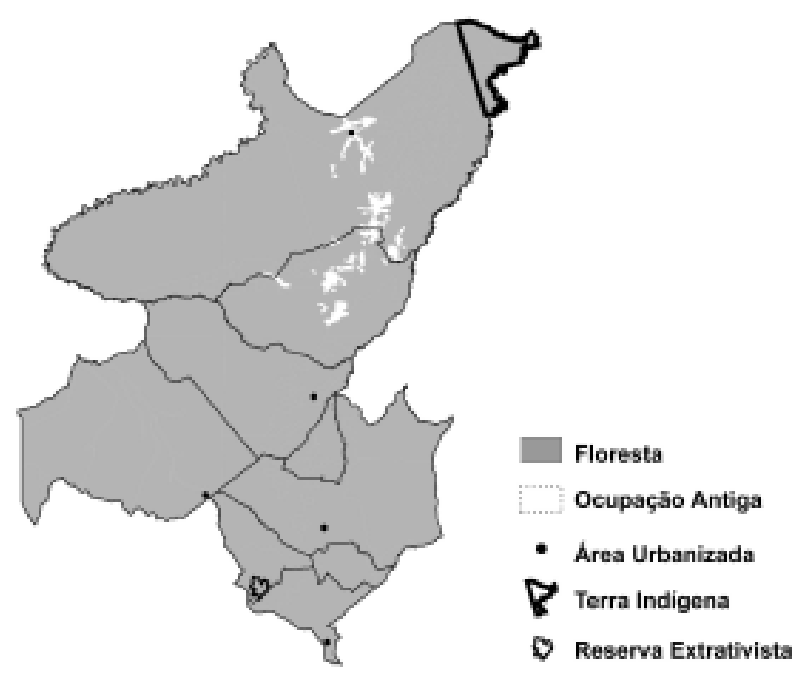

Figura 2 - Áreas originais de ocorrência de formações florestais sobre as quais recai a obrigatoriedade de manutenção de reserva legal.

Figure 2 - Original areas of forest vegetation occurrences, where legal reserve must be maintained.

R. Árvore, Viçosa-MG, v.27, n.6, p.871-877, 2003 
Quadro 2 - Área de vegetação remanescente e alterada de floresta e cerrado por município Table 2 - Remaining areas of Forest and Savana and disturbed areas in each municipality

\begin{tabular}{|c|c|c|c|c|c|c|c|}
\hline Município & UF & $\begin{array}{c}F_{R} \\
\text { Floresta } \\
\text { Remanescente }\end{array}$ & $\begin{array}{c}F_{A} \\
\text { Floresta } \\
\text { Alterada }\end{array}$ & $\begin{array}{c}P_{F R} \\
\text { Floresta } \\
\text { Remanescente }\end{array}$ & $\begin{array}{c}C_{R} \\
\text { Cerrado } \\
\text { Remanescente }\end{array}$ & $\begin{array}{c}C_{A} \\
\text { Cerrado } \\
\text { Alterado }\end{array}$ & $\begin{array}{c}P_{C R} \\
\text { Cerrado } \\
\text { Remanescente }\end{array}$ \\
\hline & & \multicolumn{2}{|c|}{$\frac{1}{\left(\mathrm{~km}^{2}\right)}$} & $(\%)$ & \multicolumn{2}{|c|}{$\frac{1}{\left(\mathrm{~km}^{2}\right)}$} & $(\%)$ \\
\hline Dom Eliseu & PA & 3319,41 & 1943,04 & 63,08 & 0,00 & 0,00 & -- \\
\hline Paragominas & PA & 12168,94 & 5553,92 & 68,66 & 0,00 & 0,00 & "3-"-" \\
\hline Rondon do Pará & PA & 5152,40 & 3081,69 & 62,57 & 0,00 & 0,00 & -- \\
\hline Ulianópolis & PA & 2980,34 & 1751,68 & 62,98 & 0,00 & 0,00 & ---- \\
\hline Acailândia & MA & 1499,93 & 4892,73 & 23,46 & 0,00 & 0,00 & - \\
\hline Cidelândia & MA & 639,62 & 736,25 & 46,49 & 0,00 & 0,00 & -"--"'-" \\
\hline Imperatriz & MA & 698,80 & 746,43 & 48,35 & 4,50 & 8,57 & 34,41 \\
\hline Itinga do Maranhão & MA & 55,84 & 808,52 & 6,46 & 0,00 & 0,00 & --- \\
\hline São Francisco do Brejão & MA & 288,65 & 442,39 & 39,49 & 0,00 & 0,00 & "3--- \\
\hline
\end{tabular}

Os valores obtidos para o indicador das áreas de remanescentes de vegetação disponíveis para manutenção de reserva legal estão no Quadro 2, juntamente com as áreas de Floresta e Cerrado remanescentes e alteradas.

Observa-se, no Quadro 2, que somente o município de Imperatriz apresenta uma parcela, e muito pequena, de seu território em área de Cerrado e que o porcentual de remanescentes de Cerrado se aproxima do mínimo estabelecido pela legislação para manutenção de reserva legal $(35 \%)$.

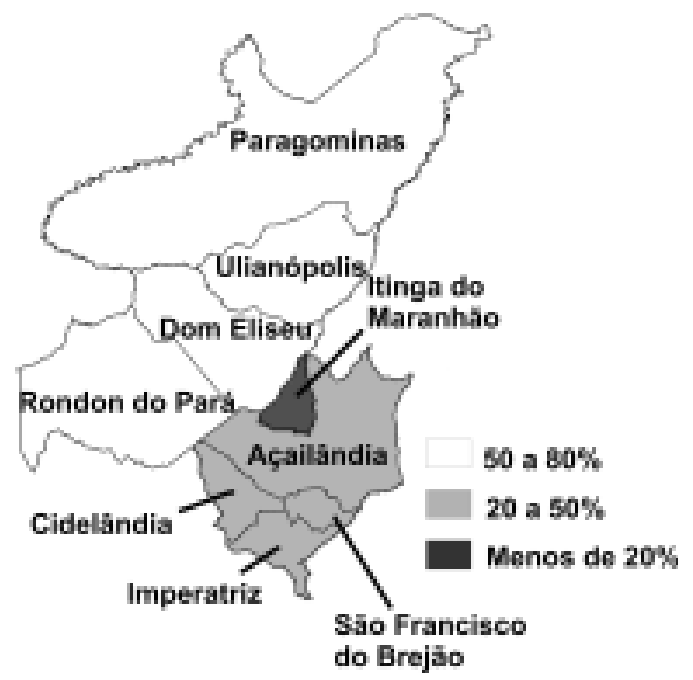

Figura 3-Porcentual de remanescentes de floresta disponível para manutenção de reserva legal por município.

Figure 3-Remaining Forest (\%) available for maintaining the legal reserve areas in each municipality.

R. Árvore, Viçosa-MG, v.27, n.6, p.871-877, 2003
Para as áreas de Floresta, observa-se que nenhum município apresenta o porcentual mínimo de remanescentes estabelecido para manutenção de reserva legal (80\%). Os municípios estudados do Pará apresentam sua área de remanescentes um pouco superior a $60 \%$. No Maranhão, os municípios estudados apresentam valores mais baixos, inferiores a $50 \%$, chegando a $6,46 \%$ em Itinga do Maranhão.

Na Figura 3, os municípios estão classificados em função do porcentual de remanescentes de Floresta que possuem: de 0 a $20 \%$, de 20 a $50 \%$ e de 50 a $80 \%$. Esses valores foram escolhidos em função das propostas atualmente em discussão sobre o porcentual mínimo de reserva legal a ser mantida nas áreas de Floresta da Amazônia Legal Brasileira.

\section{CONCLUSÃO}

A integração dos dados do Projeto RADAMBRASIL (limites originais de ocorrência das formações vegetais), do SIUC (limites das unidades de conservação e terras indígenas) e do uso e da cobertura atual das terras (vegetação remanescente) permitiu a obtenção de um indicador da proporção de vegetação remanescente disponível para manutenção de reserva legal. Esse indicador, por ser obtido a partir de dados espacializados, permite a análise da distribuição de seus valores pela região.

Os resultados obtidos evidenciaram o reduzido porcentual de remanescentes de Floresta nos municípios estudados, considerando a proporção estabelecida legalmente. No caso, todos os municípios apresentaram valores inferiores a $80 \%$. 
Estudos como este, desenvolvidos em outras áreas da Amazônia Legal Brasileira, são necessários para melhor compreender a situação atual de conservação das florestas, subsidiando o debate sobre a proporção destas a ser delimitada como reservas legais.

\section{REFERÊNCIAS BIBLIOGRÁFICAS}

ALVES, D. S.; SKOLE, D. L. Characterizing land cover dynamics using multitemporal imagery. International Journal of Remote Sensing, v. 17, n. 4, p. 835-839, 1996.

BARROSO, L. V.; BROWN, I. F.; NEPSTAD, D. C. Dinâmica do uso da terra em assentamentos humanos na região de Paragominas, Amazônia brasileira, através de sensoriamento remoto e sistema geográfico de infor mação. In: Congresso Florestal Brasileiro, 7.; Congresso Florestal Panamericano, 1., 1993, Curitiba. Anais... Curitiba: 1993. v. 2 , p. $338-340$.

BATISTA, G. T. et al. A new approach for deforestation assessment. In: INTERNATIONAL SYMPOSIUM ON RESOURCE AND ENVIRONMENTAL MONITORING, 1994, Rio de Janeiro. Proceedings... Rio de Janeiro: ISPRS Commission VII, 1994. v. 30, Part 7a, p. 170-174.

BINS, L. S.; ERTHAL, G. J.; FONSECA, L. M. G. Um método de classificação não-supervisionada por regiões. In: Simpósio Brasileiro de Computação Gráfica e Processamento de Imagens, 5., 1992, Águas de Lindóia. Anais... São José dos Campos: INPE, 1992. v. 2, p. 65-68.

CREPANI, E.; DUARTE, V.; SHIMABUKURO, Y. E. Sensoriamento remoto e geoprocessamento no mapeamento regional da cobertura e uso atual da terra. São José dos Campos: INPE, 2001. 22 p. (INPE-8478NTC/346).

DUARTE, V. et al. Metodologia para criação do PRODES Digital e do banco de dados digitais da Amazônia - Projeto BADDAM. São José dos Campos: INPE, 1999. 33 p. (INPE-7032-PUD/035).
MORAN E, F. et al. Integrating Amazonian vegetation, land-use, and satellite data. BioScience, v. 44, n. 5, p. 329338, 1994.

PROJETO RADAMBRASIL. Mapa Fitoecológico. Folhas SA-22 Belém, SA-23/24 São Luís/Fortaleza, SB/SC-22 Araguaia/Tocantins, SB-23/24 Teresina/Jaguaribe, escala 1:1.000.000. 1973/74.

SANO, E. E. et al. Levantamento do uso atual da terra através de imagens TM/Landsat na microregião de ToméAçu e alguns municipios das microregiões do Baixo Tocantins e Guajarina (PA). Belém: SUDAM-CHSRA/ OEA, 1989. $67 \mathrm{p}$.

SANTOS, J. R.; SANTOS, A. P.; AQUINO, L. C. S. Avaliação da cobertura vegetal e uso da terra nas áreas programa do PDRI-AM, através da técnica de sensoriamento remoto. São José dos Campos: INPE, 1983. 68 p. (INPE-NTE/199).

SHIMABUKURO, Y. E.; SANTOS, J. R.; AQUINO, L. C. $S$. Vegetation survey in Amazonia using Landsat data. São José dos Campos: INPE, 1982. 7 p. (INPE-2409-PRE/ 118).

SHIMABUKURO, Y. E.; SMITH, J. A. The least-squares mixing models to generate fraction images derived from remote sensing multispectral data. IEEE Transactions on Geoscience and Remote Sensing, v. 29, p. 16-20, 1991.

TARDIN, A. T. et al. Levantamento de áreas de desmatamento na Amazônia Legal a través de imagens do satélite Landsat. São José dos Campos: INPE, 1979. (INPE-1411-NTE/142).

ZUCKER, S. W. Region growing: childhood and adolescence. Computer Graphics and Image Processing, v. 5, p. 382-399, 1976. 